\title{
Diurnal variation in gravity wave activity at low and middle latitudes
}

\author{
V. F. Andrioli ${ }^{1}$, D. C. Fritts ${ }^{2}$, P. P. Batista ${ }^{1}$, B. R. Clemesha ${ }^{1}$, and D. Janches ${ }^{3}$ \\ ${ }^{1}$ Instituto Nacional de Pesquisas Espaciais - INPE, São José dos Campos, SP, Brazil \\ ${ }^{2}$ GATS/Boulder, Boulder, CO, USA \\ ${ }^{3}$ Space Weather Lab., Mail Code 674, GSFC/NASA, Greenbelt, MD 20771, USA \\ Correspondence to: V. F. Andrioli (vania@laser.inpe.br)
}

Received: 2 July 2013 - Revised: 17 October 2013 - Accepted: 29 October 2013 - Published: 29 November 2013

\begin{abstract}
We employ a modified composite day extension of the Hocking (2005) analysis method to study gravity wave $(\mathrm{GW})$ activity in the mesosphere and lower thermosphere using 4 meteor radars spanning latitudes from $7^{\circ} \mathrm{S}$ to $53.6^{\circ} \mathrm{S}$. Diurnal and semidiurnal modulations were observed in GW variances over all sites. Semidiurnal modulation with downward phase propagation was observed at lower latitudes mainly near the equinoxes. Diurnal modulations occur mainly near solstice and, except for the zonal component at Cariri $\left(7^{\circ} \mathrm{S}\right)$, do not exhibit downward phase propagation. At a higher latitude (SAAMER, 53.6 ${ }^{\circ} \mathrm{S}$ ) these modulations are only observed in the meridional component where we can observe diurnal variation from March to May, and semidiurnal, during January, February, October (above $88 \mathrm{~km}$ ) and November. Some of these modulations with downward phase progression correlate well with wind shear. When the wind shear is well correlated with the maximum of the variances the diurnal tide has its largest amplitudes, i.e., near equinox. Correlations exhibiting variations with tidal phases suggest significant GW-tidal interactions that have different characters depending on the tidal components and possible mean wind shears. Modulations that do not exhibit phase variations could be indicative of diurnal variations in $\mathrm{GW}$ sources.
\end{abstract}

Keywords. Meteorology and atmospheric dynamics (Waves and tides)

\section{Introduction}

Large-scale dynamics in the mesosphere and lower thermosphere (MLT) are strongly influenced by smaller-scale gravity waves (GWs) owing to significant GW momentum transport and deposition accompanying GW propagation and dissipation. Because GW dissipation is strongly influenced by large-scale wind shears, GW propagation and momentum transport are expected to be strongly modulated by the various tidal and planetary wave (PW) motions (e.g., Walterscheid, 1981; Fritts and Alexander, 2003). Indeed, a number of previous observations have revealed strong modulations of GW variances and momentum fluxes, suggesting significant interactions with the tides and PWs. MF and VHF radars have indicated (1) peaks in GW variance spectra at tidal and PW periods (Isler and Fritts, 1996; Manson et al., 1998) and (2) an approximate anti-phase relationship between tidal winds and GW momentum fluxes (Fritts and Vincent, 1987; Wang and Fritts, 1991). Modelling studies have suggested both tidal amplitude reductions and/or phase advances (Forbes et al., 1991; Lu and Fritts, 1993; Meyer, 1999) and amplitude enhancements (Mayr et al., 1998), depending on the GW parameterization used. Ortland and Alexander (2006) demonstrated that these influences depend strongly on the phase speed distribution and isotropy of the GW spectrum.

Meteor radars can also contribute to studies of GW-tidal and GW-PW interactions through definition of the largescale motions and the GW variances and momentum fluxes. Studies of GW variances or momentum fluxes to date have addressed primarily seasonal variations (e.g., Antonita et al., 2008; Beldon and Mitchell, 2010; Fritts et al., 2010, 2012a; Placke et al., 2011a), most using the Hocking (2005) analysis method or a derivative thereof. The Hocking (2005) method in principle allows the use of meteor radar data to estimate the large-scale motions as well as all GW variances and momentum fluxes. This has enabled significant advances 


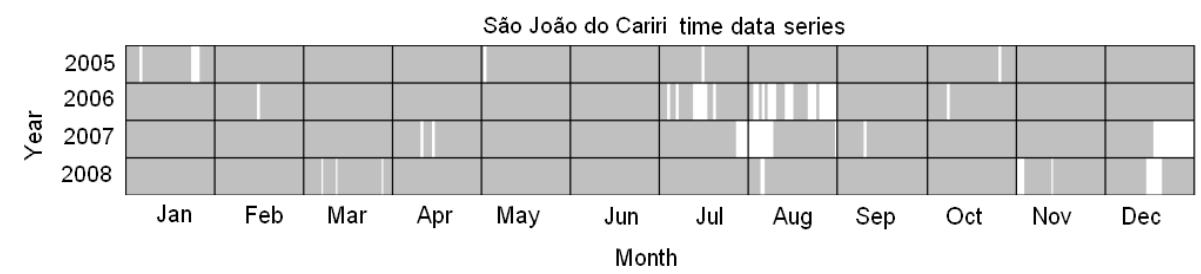

Fig. 1. Available data series for the meteor radar located at Cariri. The blank blocks indicate data gaps.

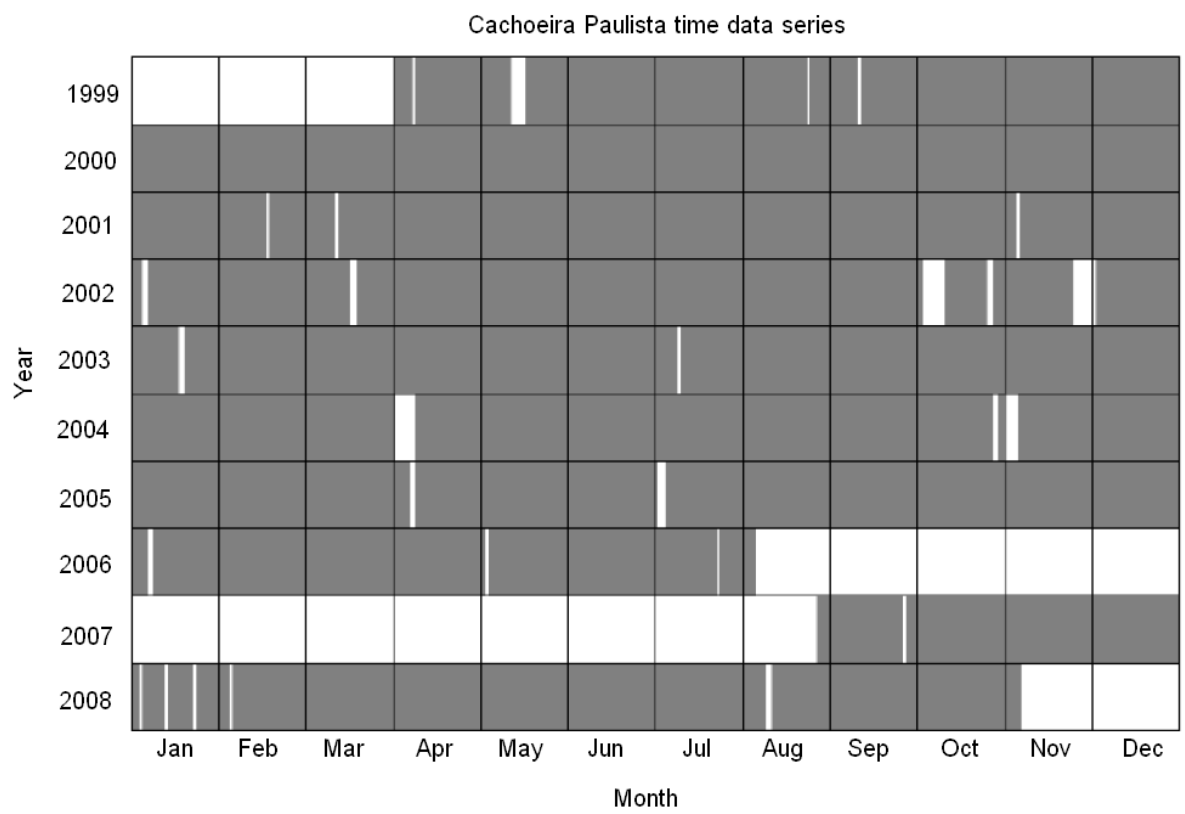

Fig. 2. The same as Fig. 1 but for the meteor radar at CP.

in studies of GW propagation and effects in the MLT, given the worldwide network of meteor radars that operate almost continuously.

Despite the benefits of the Hocking (2005) method, there are biases that arise in the estimates of GW variances and momentum fluxes due to the spatial and temporal averaging required to form these estimates with sufficiently small uncertainties. Vertical wind shears and temporal wind variations both contribute to increased apparent $\mathrm{GW}$ variances and biased momentum fluxes unless corrections are applied. Placke et al. (2011a, b) attempted to account for vertical wind shears, while Andrioli et al. (2013) examined both effects and provided a modified composite day (MCD) analysis method that overcomes the more general problem.

In this paper we present GW variance estimates obtained by applying the MCD version of the Hocking (2005) technique using meteor radars at several latitudes. Findings include diurnal and semidiurnal modulations of $\mathrm{GW}$ variances exhibiting good correlations with tidal wind shears in several cases. Our findings provide additional evidence for strong GW-tidal interactions observed in previous studies. These dynamics probably also include generation of additional
GWs accompanying these interactions, given the expectation for secondary GW generation in regions of strong dissipation and momentum deposition (Vadas and Fritts, 2001, 2002). Meteor radar measurements are probably not able to measure these responses, however, because any secondary GWs generated at these altitudes will only yield large amplitudes and variances at higher altitudes.

\section{Method}

Hocking's (2005) analysis assumes that winds in the MLT region are uniform on a horizontal plane and that any difference between a given measured meteor radial velocity and the fitted radial wind velocity is due to the contribution of GWs. On this basis it is possible to compute the meridional, zonal, and vertical fluctuating wind velocities and the vertical flux of horizontal momentum (see Hocking, 2005 , for details). In the present paper we apply the MCD extension of the Hocking (2005) method to data from four all-sky meteor radars. The MCD analysis involves a simple change in the way in which traditional composite day estimates are constructed. This involves a pre-analysis that infers 


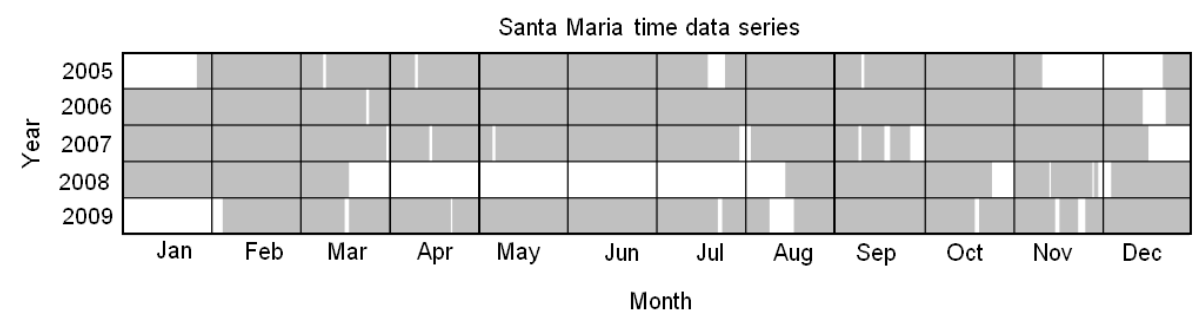

Fig. 3. The same as Fig. 1 but for the meteor radar at SM.
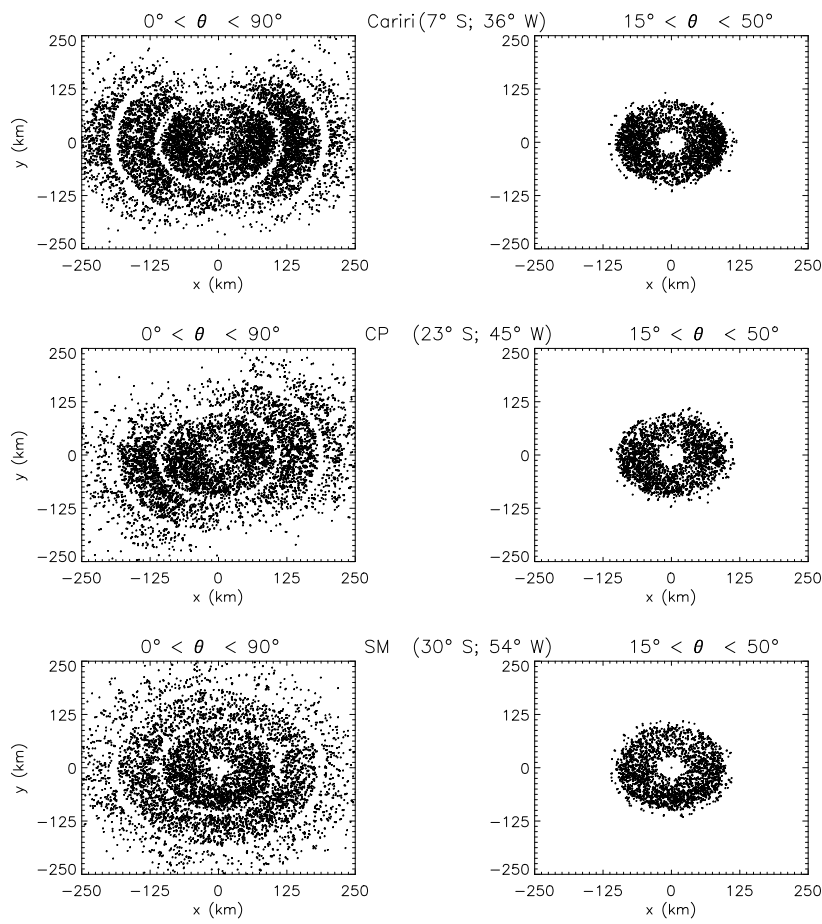

Fig. 4. Daily meteor distributions, for 1 June 2005, illustrating the azimuth patterns of the three Brazilian radars employed in this work. (Left) Meteor distribution including all the zenith angles and (right) only the meteors used in the analysis. The location of each of the radars is listed in each panel.

the differences between individual radial velocities and best fit radial velocities (hereafter referred to as $v_{\text {rad }}^{\prime}$ ) for each time interval and day separately, and associates them with the meteor position information throughout the entire data set. After this procedure, we then apply the Hocking (2005) technique and compute the GW wind variances and vertical fluxes of horizontal momentum. In this way we can use a composite day analysis but avoid the effects of day-to-day changes in tides and PWs. Furthermore, using MCD we can accumulate more echoes in each height/time interval, and the larger the meteor count the greater is the confidence in the results.

The data were analysed using a height interval of $4 \mathrm{~km}$ width (centered at $82,85,88,91,94$, and $98 \mathrm{~km}$ ), a $3 \mathrm{~h}$ time interval (centered at 01:00, 03:00, 05:00, 07:00, 09:00, 11:00,
13:00, 15:00, 17:00, 19:00, 21:00, 23:00 UT), and zenith angles between 15 and 50 degrees. The latter constraint avoids spurious contributions to large GW variances due to large vertical velocities at small zenith angles and range errors due to zenith angle uncertainties at low elevation angles. This analysis allows us to study GWs with periods less than $\sim 3 \mathrm{~h}$, vertical wavelengths less than $\sim 5-10 \mathrm{~km}$, and horizontal wavelength less than $\sim 180 \mathrm{~km}$. Additional details of the method can be found in Andrioli et al. (2013).

We analyze the data from three SKiYMET meteor radars and the Southern Argentina Agile MEteor Radar (SAAMER), which are well distributed in latitude, including São João do Cariri (Cariri) at $7^{\circ} \mathrm{S} ; 36^{\circ} \mathrm{W}$, Cachoeira Paulista $(\mathrm{CP})$ at $23^{\circ} \mathrm{S} ; 45^{\circ} \mathrm{W}$, Santa Maria (SM) at $30^{\circ} \mathrm{S} ; 54^{\circ} \mathrm{W}$, and SAAMER on Tierra del Fuego at $53.8^{\circ} \mathrm{S} ; 67.8^{\circ} \mathrm{W}$. With the exception of SAAMER, where we used only the data for 2010, our analysis employs all available data. The results presented here represent monthly means for each radar for all available years. Figures 1, 2, and 3 show the available data series from Cariri, CP, and SM, respectively. The blank blocks represent data gaps when, for various reasons, the radars did not operate. The SAAMER data used are from January to December of 2010 when the radar worked nearly continuously, with only five days without data. We can see from these figures that there are approximately four, nine, and five years of data for Cariri, CP, and SM, respectively.

As the Hocking (2005) analysis is a generalization of the Vincent and Reid (1983) dual-beam technique, the azimuthal meteor distribution has an important influence on the accuracy of the analysis. Fritts et al. (2012b) have shown that the best efficiency of Hocking's analysis is achieved when the meteor counts in opposing directions are large. Figure 4 shows the daily meteor distributions in zenith angle and azimuth for the three Brazilian radars observed on 1 June 2005. Note that SM uses a crossed Yagi transmitting antenna and, for this reason, it has a more uniform radiation pattern. In contrast, CP and Cariri use linear Yagi transmitting antennas. Nevertheless, for the zenith angles from $15^{\circ}$ to $50^{\circ}$ employed for our studies, all radars have reasonably uniform azimuthal sensitivities. This means that the MCD version of the Hocking (2005) method should work well for all radars. Daily meteor distributions for SAAMER are shown in Fritts et al. (2010, 2012a, b). 

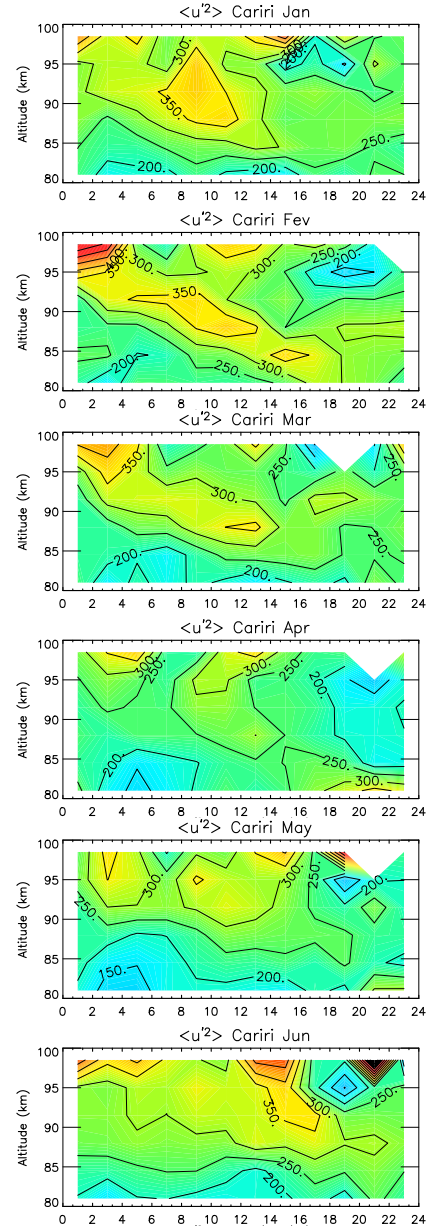
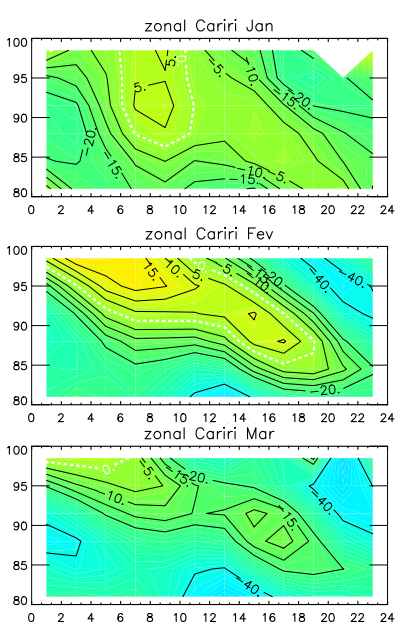

zonal Cariri Apr
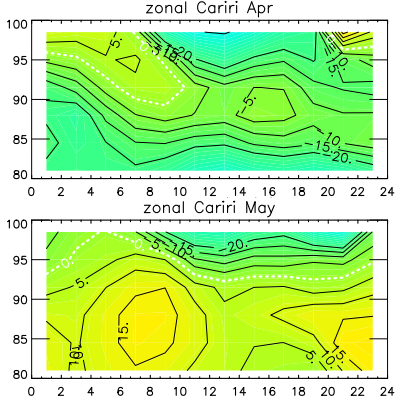

zonal Cariri Jun

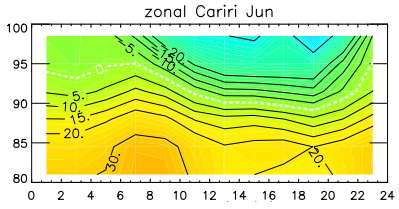

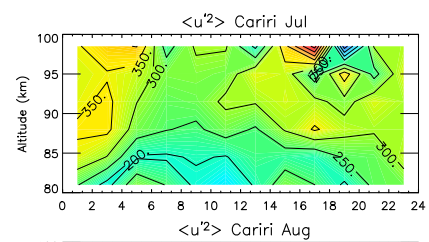
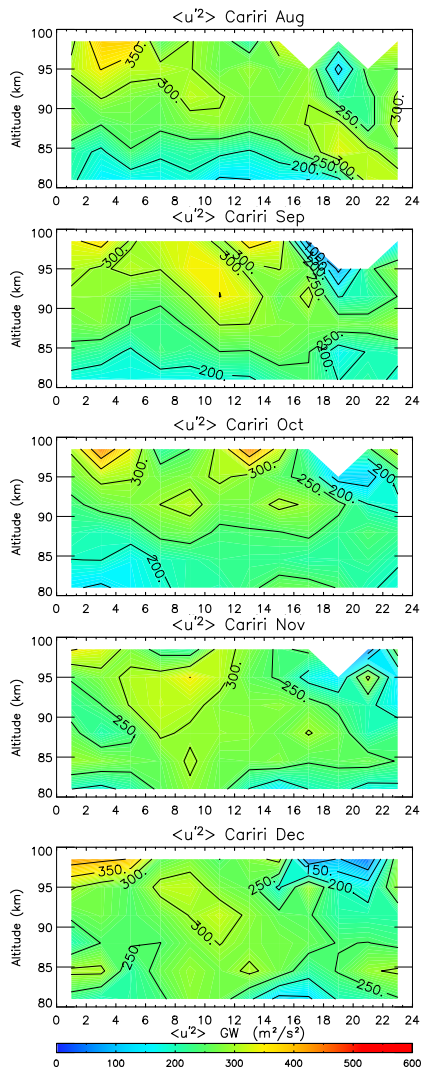
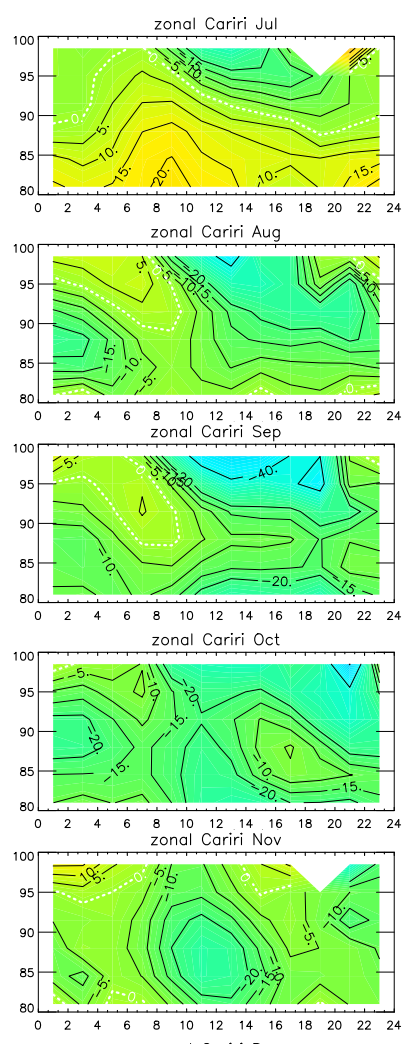

zonal Cariri Dec

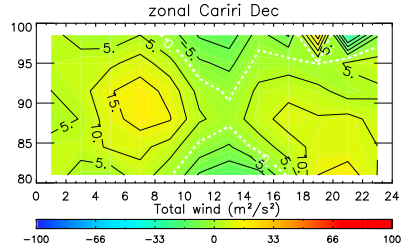

Fig. 5. Zonal component of variances (left side) and the total wind (right side) averaged from 2005 to 2008 over São João do Cariri. All panels show the height/time variation of their respective variable. The altitude is measured in $\mathrm{km}$, and the $x$ axis represents Universal Time (UT) beginning at midnight, and each line of the variances contour plot corresponds to $50 \mathrm{~m}^{2} \mathrm{~s}^{-2}$. The total wind is measured in m s the white dashed line indicates where the values are zero.

It should also be remembered that $\mathrm{GW}$ variances are likely to be somewhat more uncertain where meteor counts are lower, hence at higher and lowest altitudes. This is because Hocking's analysis is not as well conditioned with fewer meteor counts.

\subsection{Method for removing tidal biases from the Hocking variance analysis}

Andrioli et al. (2013) developed an empirical technique to remove the apparent variances from the Hocking analysis, leaving only estimates of the radial velocities due to GW motions (e.g., the MCD method). In the present work we use the MCD method in order to analyse the GW variances and their correlations with tidal winds and shears over the 4 radars. This method involves three steps. Step 1 infers the tidal fields and total variances using Hocking's method. Step 2 employs the tidal parameters obtained in Step 1 as input for a fit to the large-scale wind field that varies smoothly in space and time. This allows, in Step 3, more accurate estimates of individual radial velocities and resulting GW variances. The fits in Step 2 are performed using the measured meteor parameters, including the position of each detected meteor, and replacing the measured radial velocity by that calculated from the model, using Eqs. (1), (2), (3) and (4) below. Finally, we subtract the apparent variances from the total, leaving only the variances due to GWs. Additional details are provided by Andrioli et al. (2013).

$$
\begin{aligned}
U(x, y, z, t) & =U_{\mathrm{M}}+U_{\mathrm{D}}(z, t) \sin \left(2 \pi\left(t-\delta_{\mathrm{UD}}\right) / T_{\mathrm{D}}\right) \\
& +U_{\mathrm{SD}}(z, t) \sin \left(2 \pi\left(t-\delta_{\mathrm{USD}}\right) / T_{\mathrm{SD}}\right) \\
V(x, y, z, t) & =V_{\mathrm{M}}-V_{\mathrm{D}}(z, t) \cos \left(2 \pi\left(t-\delta_{\mathrm{VD}}\right) / T_{\mathrm{D}}\right) \\
& -V_{\mathrm{SD}}(z, t) \cos \left(2 \pi\left(t-\delta_{\mathrm{VSD}} /\right) / T_{\mathrm{SD}}\right)
\end{aligned}
$$



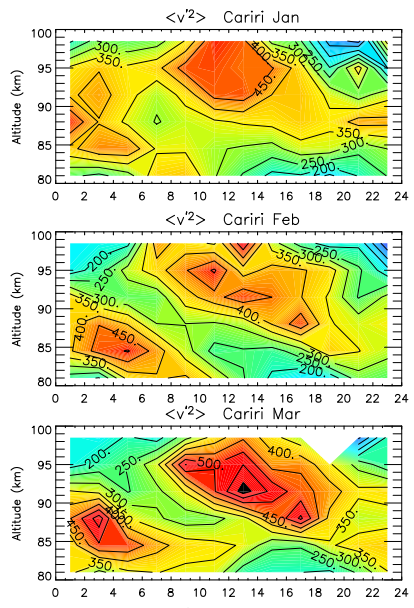

$\left\langle v^{\prime 2}\right\rangle$ Cariri Apr
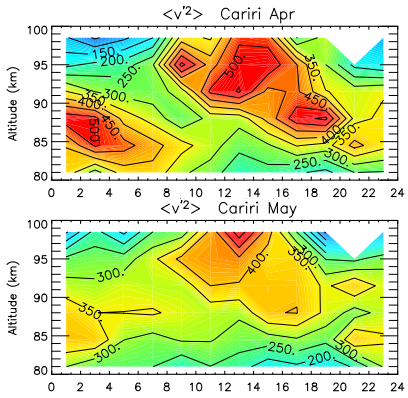

$\left\langle v^{\prime 2}\right\rangle$ Cariri Jun

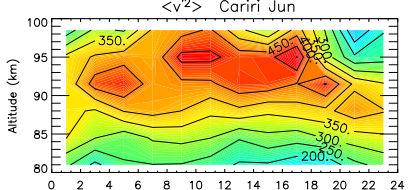

meridional Cariri Jan

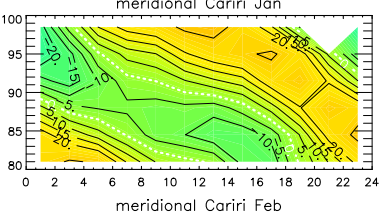

meridional Cariri Feb

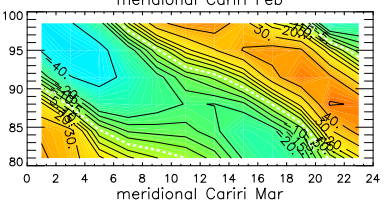

meridional Cariri Mar

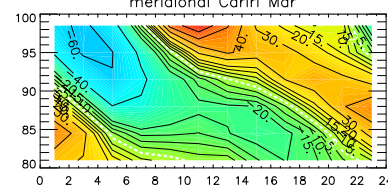

meridional Cariri Ap
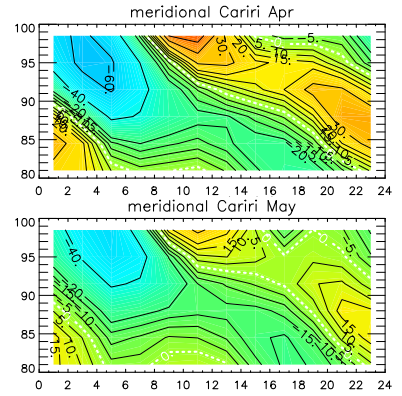

meridional Cariri Jun

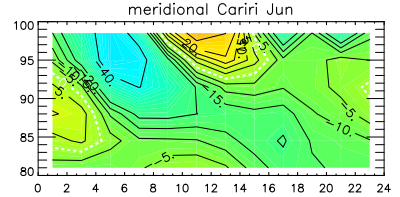

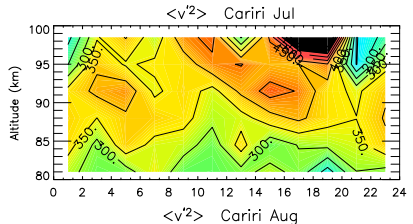
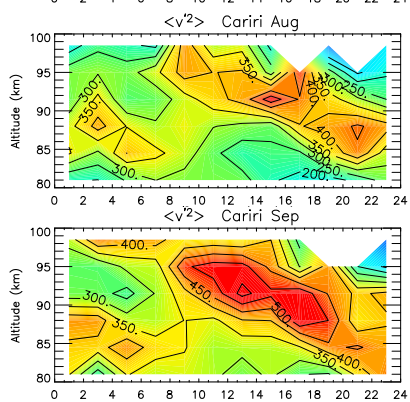

$\left\langle v^{2}\right\rangle$ Cariri Oct
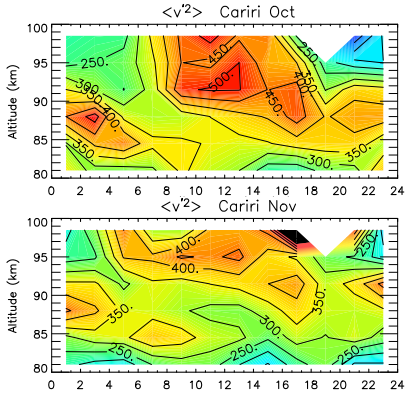

$\left\langle v^{2}\right\rangle$ Cariri Dec

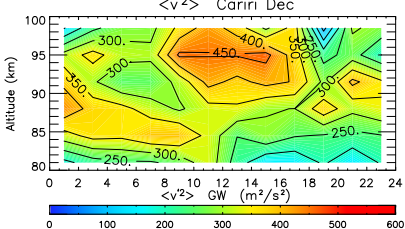

meridional Cariri Jul

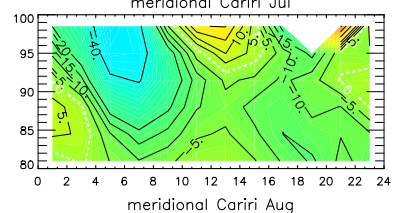

meridional Cariri Aug
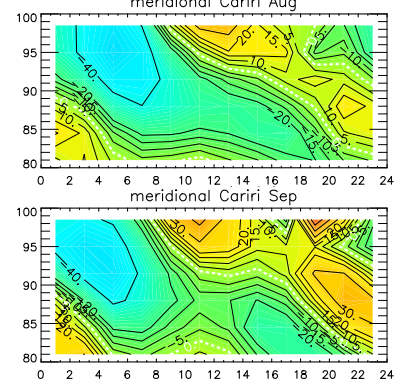

meridional Cariri Oct
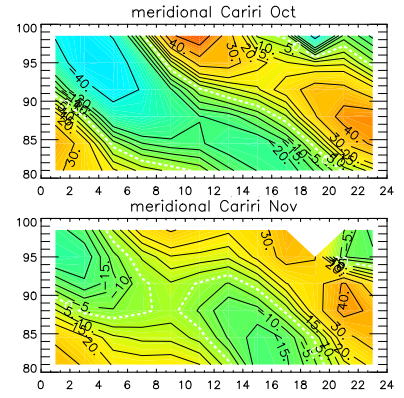

meridional Cariri Dec

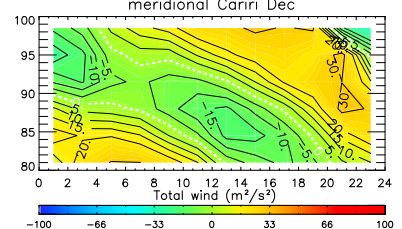

Fig. 6. The same as Fig. 5, but for the meridional component.

\section{Results}

$W(x, y, z, t)=0$

$$
\begin{aligned}
V_{\mathrm{rad}} & =U(x, y, z, t) \sin \theta \cos \varphi+V(x, y, z, t) \sin \theta \sin \varphi \\
& +W(x, y, z, t) \cos \theta
\end{aligned}
$$

Here, $U, V$, and $W$, are zonal, meridional and vertical wind velocities, $V_{\text {rad }}$ is the radial velocity calculated for each meteor zenith and azimuth position, $\theta, \varphi$, respectively, subscripts $\mathrm{M}, \mathrm{D}$, and, SD denote mean wind and diurnal and semidiurnal tides (with amplitudes assumed to vary smoothly in space and time), $(x, y, z)$ is the meteor position, and $t$ is the time when each meteor was detected. $\left(\delta_{\mathrm{UD}}, \delta_{\mathrm{VD}}\right)$ and $\left(\delta_{\mathrm{USD}}, \delta_{\mathrm{VSD}}\right)$ are diurnal and semidiurnal tidal phases varying according to the inferred vertical wavelengths, subscripts $\mathrm{U}$ and $\mathrm{V}$ refers respectively to zonal and meridional component, and $T_{\mathrm{D}}$ and $T_{\mathrm{SD}}$ are the respective tidal periods, 24 and $12 \mathrm{~h}$.
Several studies have been performed analyzing data from the three radars at Cariri, CP, and SM with a focus on tides and PWs (Andrioli et al., 2009; Batista et al., 2004; Lima et al., 2004, 2005, 2006, 2007; and Buriti et al., 2008). Although Clemesha and Batista (2008) and Clemesha et al. (2009) presented some studies of wind variances related to GWs using these data, the possible effects of tidal contamination were not taken into account. As noted above, Andrioli et al. (2013) showed that GW variances are typically contaminated by tides and suggested a method for removing this contamination, thus allowing their accurate estimate. For this reason, we re-analyze all previous data using our new MCD method. We also analyze one year of SAAMER data in order to extend our analysis to higher southern latitudes.

Figure 5 shows the zonal variances (left side) and total wind (right side) for each month averaged from 2005 to 2008 at Cariri. In this paper we refer to total wind as the entire wind measured by each radar. In each case results represent a 

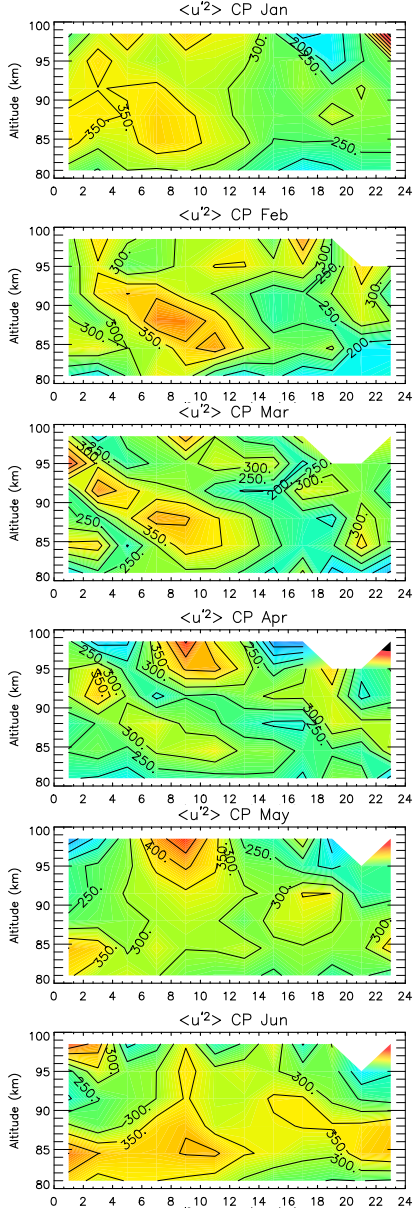
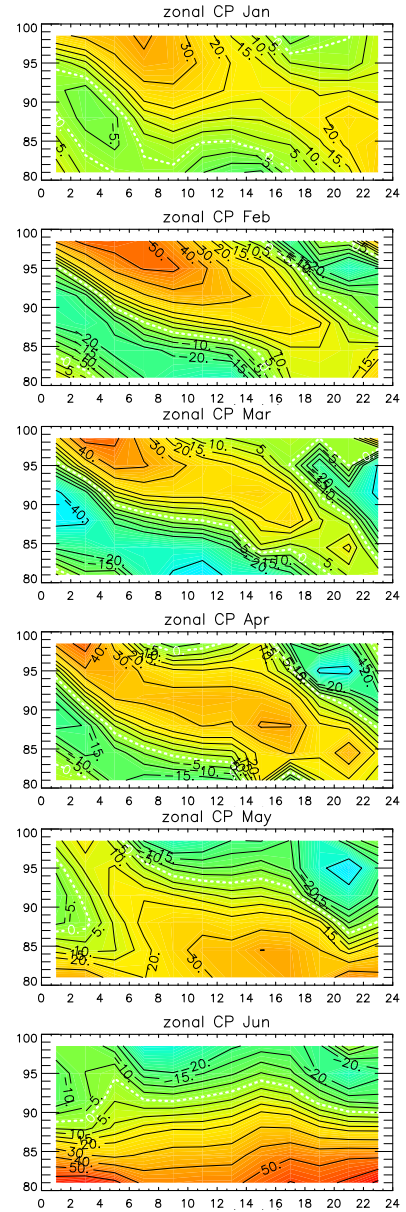
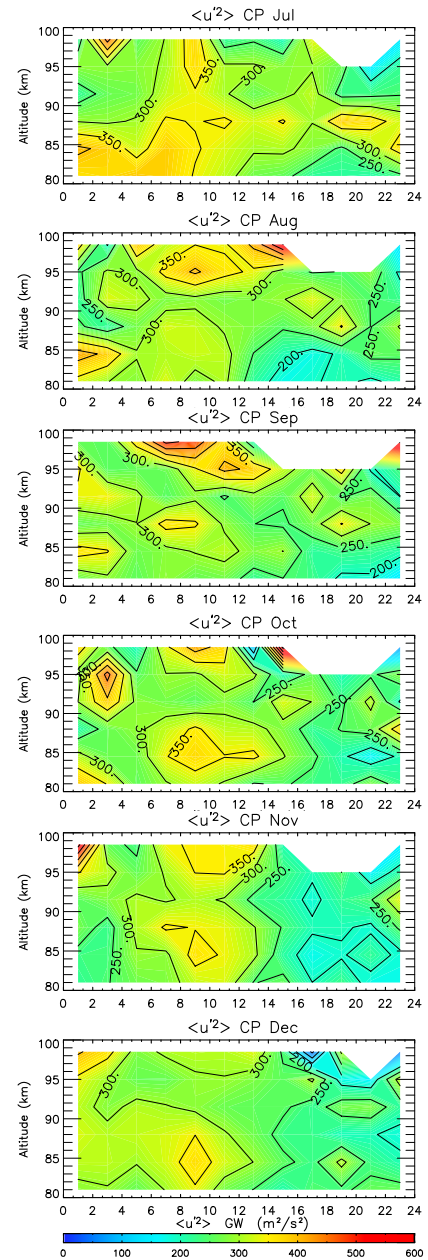
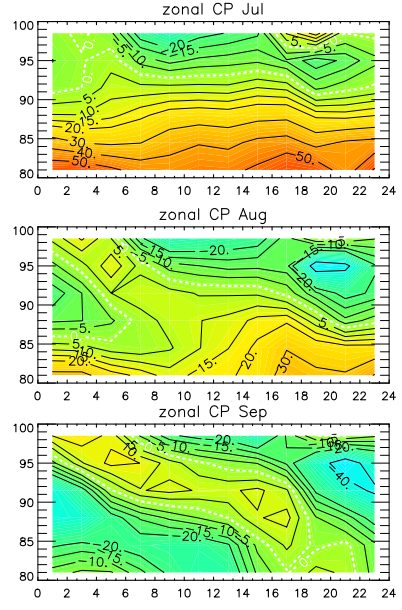

zonal CP Oct
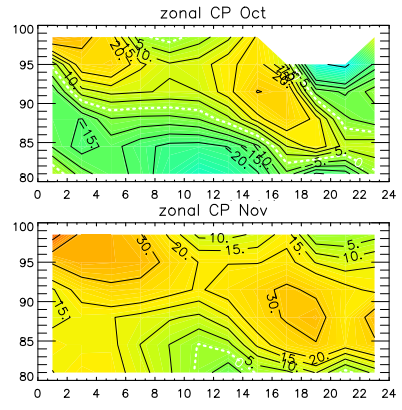

zonal CP Dec

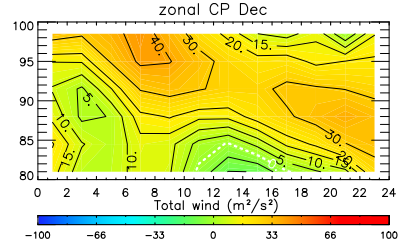

Fig. 7. The same as Fig. 5, but averaged from 1998 to 2008 over Cachoeira Paulista.

monthly mean, with each time/height interval averaged over all data available during the month. It can be seen from this figure that there is a maximum in the variances around $95 \mathrm{~km}$ and 02:00 UT, with downward phase propagation in time, reaching $85 \mathrm{~km}$ around 14:00 UT in February, March, and September, indicating a diurnal modulation. It is of interest to note that these maxima are centered where the wind changes its direction and has the stronger wind shear, represented by the dashed line. In the same figure we can see that none of the other months exhibit the downward diurnal modulation and only show variances increasing with height.

In Fig. 6, which shows meridional variances at Cariri, we can see in the months of February to April, and August to October two maxima, the first starting around $89 \mathrm{~km}$ close to midnight and the second starting around $98 /, \mathrm{km}$ at about 08:00 UT. Both of these show downward phase propagation in time and, as in the zonal component, indicate semidiurnal modulation. Again, we can see that these modulations exhibit good correlations with the stronger wind shears. It is also interesting to point out here that even from May to July, when the winds exhibit strong shears, the variances do not maximize in these regions.

Figure 7 presents the zonal variances (left side) and the total wind (right side) over CP averaged from 1998 to 2008. Here we note a semi-diurnal modulation with phase descent from February to April and in September. The first maximum begins at around $95 \mathrm{~km}$ at around 02:00 UT and progresses down to $80 \mathrm{~km}$ at around 12:00 UT, the second begins at around 10:00 UT at $98 \mathrm{~km}$ reaching $80 \mathrm{~km}$ at around 23:00 UT. For these months, the maxima in the variances agree with the maxima in the wind shears. On the other hand, January and October to December exhibit a diurnal modulation with no phase progression and no relation to the wind shear.

Figure 8 shows meridional variances on the left side and the total wind on the right, all averaged from 1998 to 2008 over CP. Here we see strong semidiurnal modulation with phase progression from February to April and in September, again with good agreement between the maxima in the variances and wind shears. On the other hand, a diurnal 

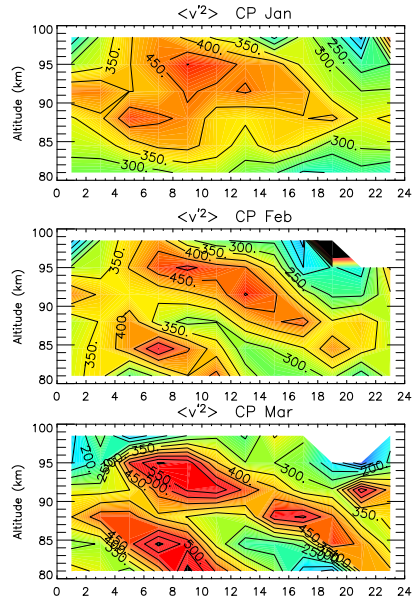

$\left\langle v^{\prime 2}\right\rangle$ CP Apr
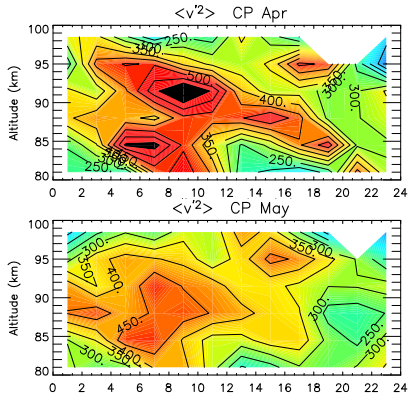

$\left\langle v^{2}\right\rangle$ CP Jun

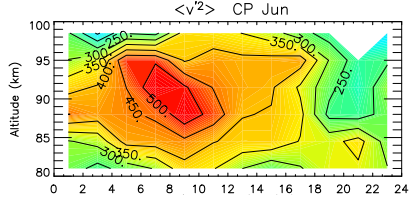

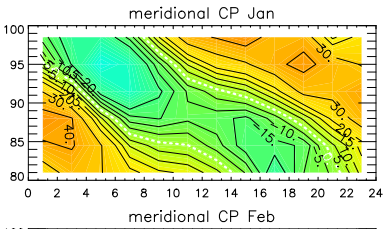
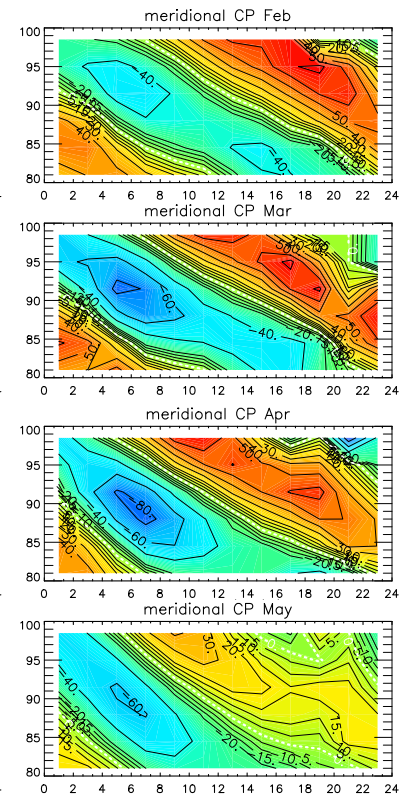

meridional CP Jun

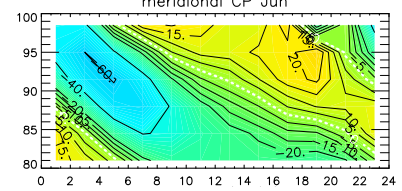

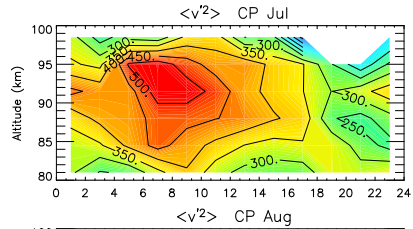
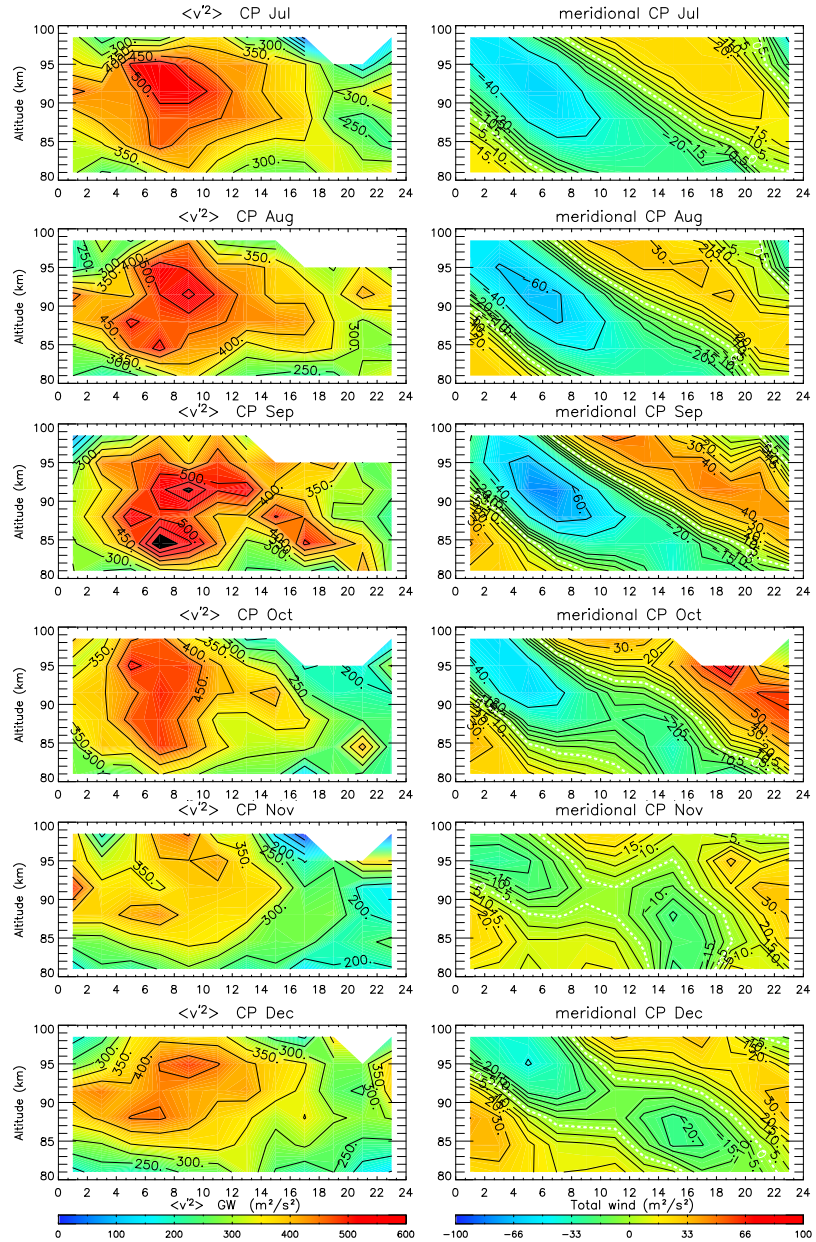

meridional CP Oct
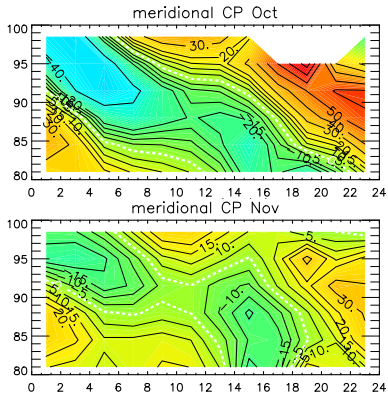

meridional $\mathrm{CP}$ Dec

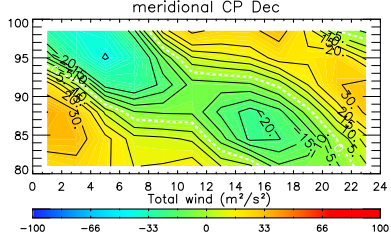

Fig. 8. The same as Fig. 7, but for the meridional component.

modulation with no phase progression and no relation to wind shear is observed from October to December and June to July.

Shown on the left side of Fig. 9 are the zonal variances for Santa Maria averaged from 2005 to 2009, with the zonal winds on the right. Semidiurnal modulation with phase progression is observed from February to April and in October. These variations are different from the diurnal variation observed at Cariri and in agreement with the observations over CP. Also, modulations observed in the equinox months are similar at the three sites; the maxima of the variances occur where the wind shears are largest. Also, diurnal modulation is observed in January, November, and December with no phase progression and no relation to the wind shear.

The meridional variances and winds are shown on the left and right in Fig. 10, respectively. A semidiurnal modulation with phase progression is observed in February and March and the maximum of this modulation accompanies the largest wind shear. Semidiurnal modulations with phase progression are also observed in September and October; however, the variance maxima do not follow the largest wind shears.
Figure 11 shows the zonal variances and winds for SAAMER during 2010. Compared to the observations made at Cariri (150 to $400 \mathrm{~m}^{2} \mathrm{~s}^{-2}$ ), CP, and SM (200 to $400 \mathrm{~m}^{2} \mathrm{~s}^{-2}$ ) shown in Figs. 5, 7, and 9, respectively, we can note that the variances observed at SAAMER (250$600 \mathrm{~m}^{2} \mathrm{~s}^{-2}$ ) are larger than those observed at the other three locations. Although not so evident as in the zonal component, meridional variances at SAAMER are also larger than those observed at the other three sites, comparing Fig. 12 with Figs. 6, 8, and 10. This is more apparent in a temporal average (not shown here), where the SAAMER variances can reach values larger than $440 \mathrm{~m}^{2} \mathrm{~s}^{-2}$ while at the other sites the maxima were no more than $400 \mathrm{~m}^{2} \mathrm{~s}^{-2}$. These results are consistent with the existence of a hot spot for GW generation located in the SAAMER region. The zonal values of the variances have similar behavior throughout the year, increasing with height. Even though we can observe strong wind shears in several months, no associated variance increases are observed. 

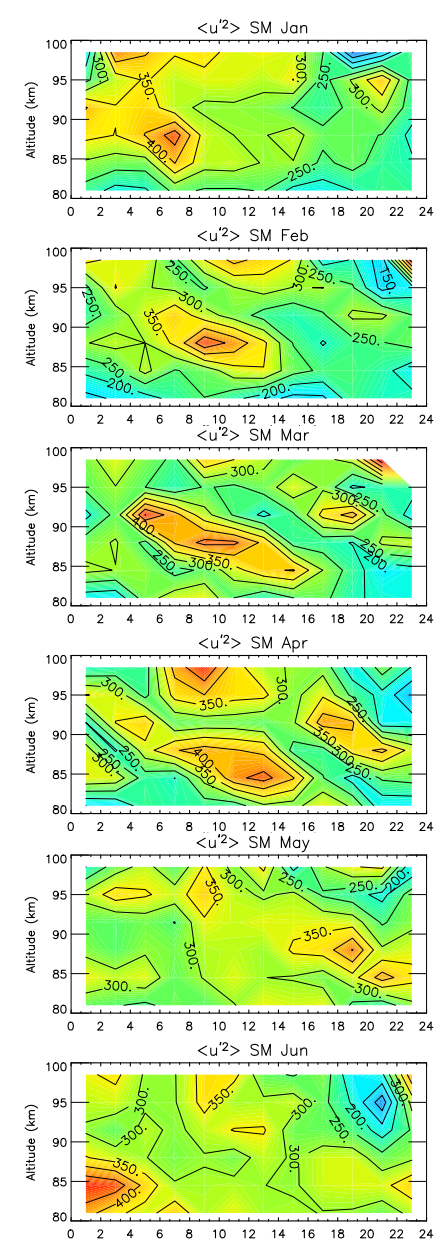
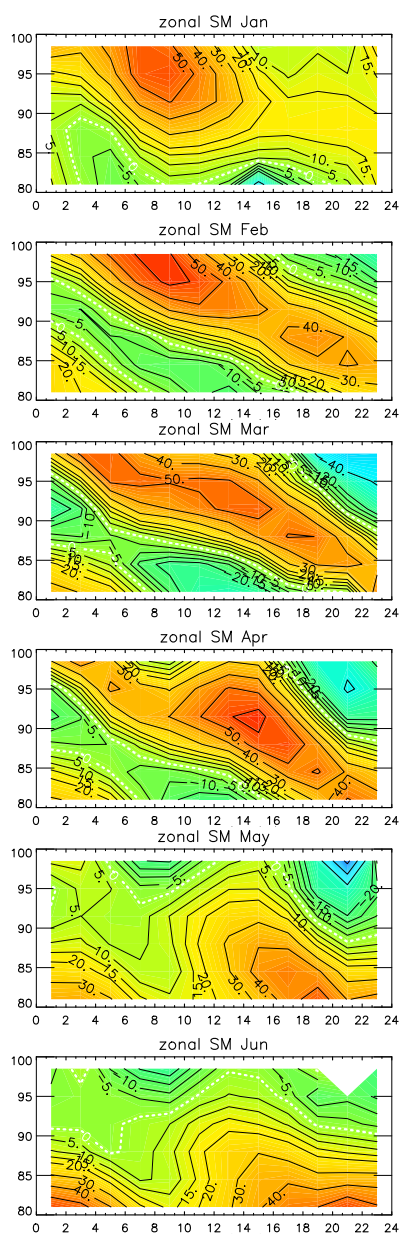
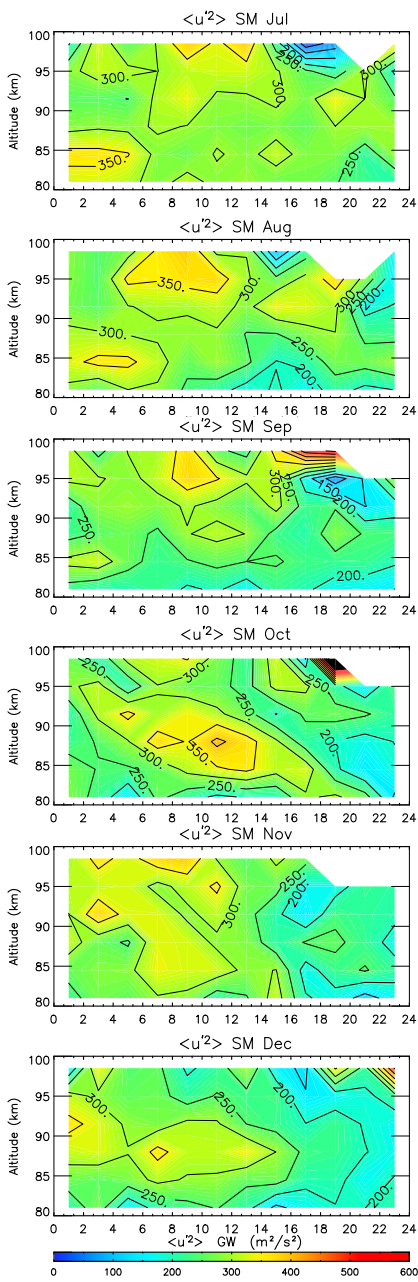

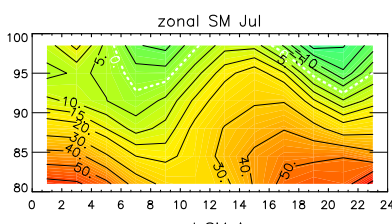

zonal SM Aug
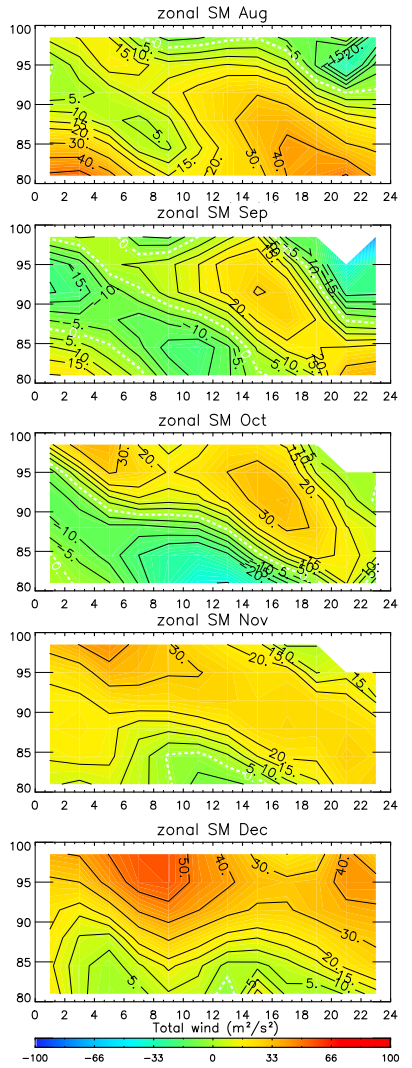

Fig. 9. Zonal component of variances (left side) and the total wind (right side) averaged from 2005-2009 over Santa Maria. All panels show the height/time variation of their respective variable. The altitude is measured in $\mathrm{km}$, the $x$ axis represents Universal Time (UT), and each line of the variances contour plot corresponds to $50 \mathrm{~m}^{2} \mathrm{~s}^{-2}$. The total wind is measured in $\mathrm{m} \mathrm{s}^{-1}$ and the dashed line indicates where the values are zero.

Figure 12 shows meridional variances and winds observed during 2010 by SAAMER. It appears that a diurnal modulation in variance exists from March to May, but with no phase progression and no relation to the wind shear. Semidiurnal modulations are observed in January, February, October (above $88 \mathrm{~km}$ ), and November, again with no phase progression and no relation to wind shear.

There is also evidence of seasonal variance variations, especially at higher southern latitudes. However, the present paper focuses only on diurnal and semidiurnal variations.

\section{Discussion}

Diurnal or semidiurnal modulations in GW variances are observed by all of the meteor radars employed for this study. At lower latitudes, Cariri, CP, and SM, these modulations occur mainly in equinox months, and with the exception of Cariri in the zonal component, all of them are semidiurnal. In addition, except for the fall equinox in the meridional component at SM, all of the semidiurnal modulations exhibit downward time phase progression. Moreover, diurnal modulations occur mainly near solstice and, except for the zonal component at Cariri, all of the others do not show downward phase progression. At SAAMER, these modulations are only observed in the meridional component, with diurnal modulation from March to May and in the semidiurnal component in January, February, October (above $88 \mathrm{~km}$ ), and November.

Several studies have shown similar modulation in GW variances at other locations. A possible explanation for the modulation in the GW fields with tidal periods has been given, among other authors, by Isler and Fritts (1996). The saturated amplitude for a single GW is typically assumed to be $|\bar{u}-c|$, where $\bar{u}$ is the mean wind and $c$ is the phase speed of the wave. A medium- or high-frequency GW also 

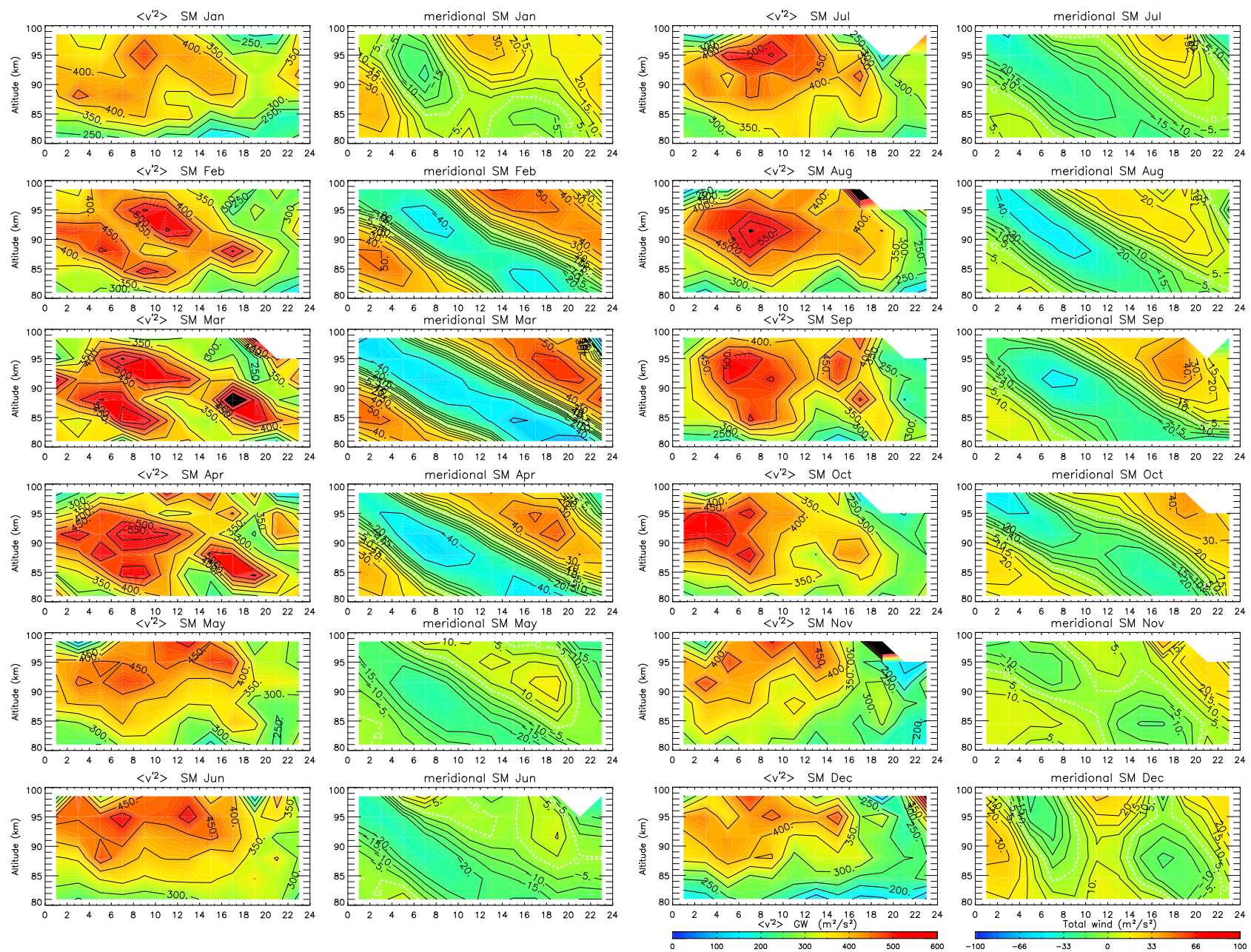

Fig. 10. The same as Fig. 9, but for the meridional component.

is typically refracted by a tidal wind field approximately as if it were a local mean wind. For a GW spectrum with phase speeds distributed about zero, a diurnal tide in the zonal wind can impose either a diurnal or a semidiurnal variation in GW variance, depending on the relative isotropy or anisotropy of the phase speed distribution. For a diurnal tide, zonal winds achieve maxima in a given direction twice a day, suggesting a possible semidiurnal variation in GW variance, but with a diurnal modulation of propagation direction (e.g., Isler and Fritts, 1996). On the other hand, a large diurnal tide superimposed on a strong mean wind can result in a diurnal variance modulation due to the asymmetry introduced by the large mean wind. Likewise, if the GW spectrum itself is anisotropic, the asymmetry of the spectrum will in general cause variance enhancements to occur at the same period as the lower-frequency motion. These examples, given by Isler and Fritts (1996), invoke filtering processes to impart a periodicity to the GW variance. Good correlation between strong increases of GW variances and wind shear, as shown previously, are consistent with the idea of tidal filtering of the GW spectrum. This is based on the removal of GWs encountering tidal shears that decrease their intrinsic phase speeds, causing them to approach critical levels and dissipate, and the strong amplitude growth of GWs in tidal shear that increase their intrinsic phase speeds. Such filtering mechanisms may explain some of the modulations at tidal periods and correlations with tidal wind shears, but they remain to be confirmed with more detailed measurements and/or quantitative modelling accounting for all of the relevant dynamics.

Another mechanism has been suggested by several authors, which really represents a sub-set of the dynamics discussed above (e.g., Walterscheid, 1981; Thayaparan et al., 1995; Manson et al., 1998). The mechanism is to again filter the GW spectrum, but by critical levels at which a GW has a horizontal phase speed equal to the background wind in the direction of GW propagation. In reality, however, critical levels represent the level below which a GW must dissipate, given the saturation limit noted above, according to linear theory. 

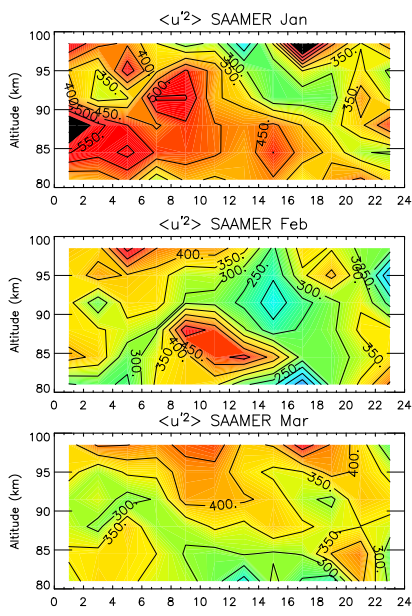

$\left\langle u^{\prime 2}\right\rangle$ SAAMER Apr
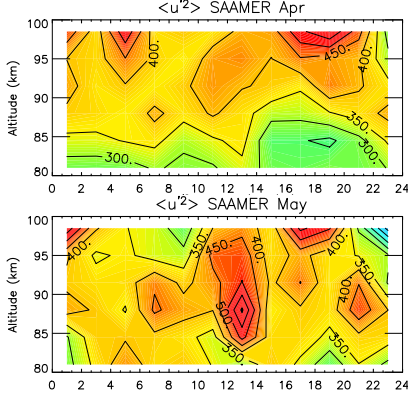

$\left\langle u^{\prime 2}\right\rangle$ SAAMER Jun

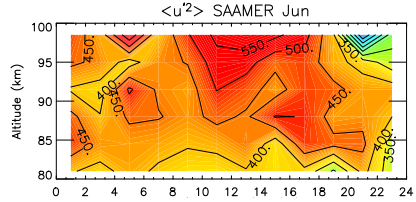

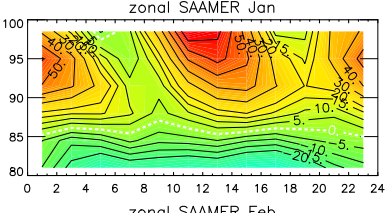

Zonal SAAMER Feb
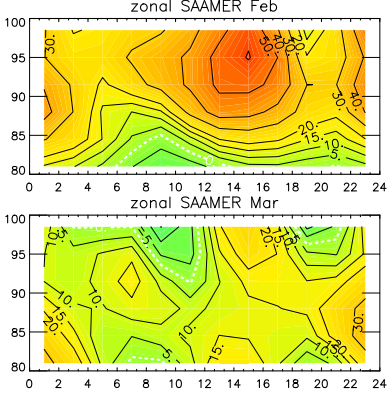

zonal SAAMER Apr
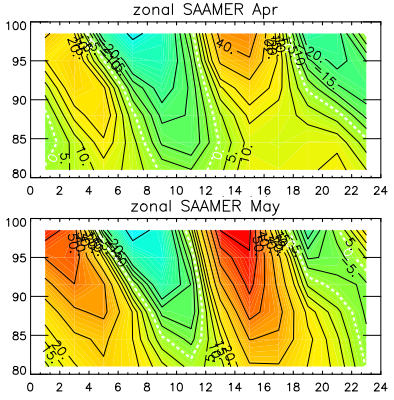

zonal SAAMER Jun

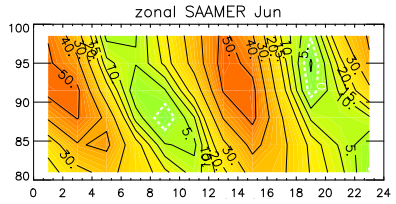

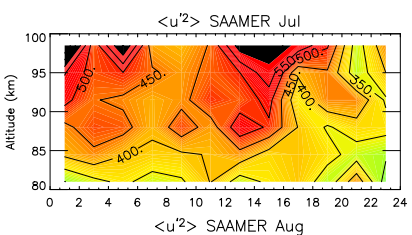
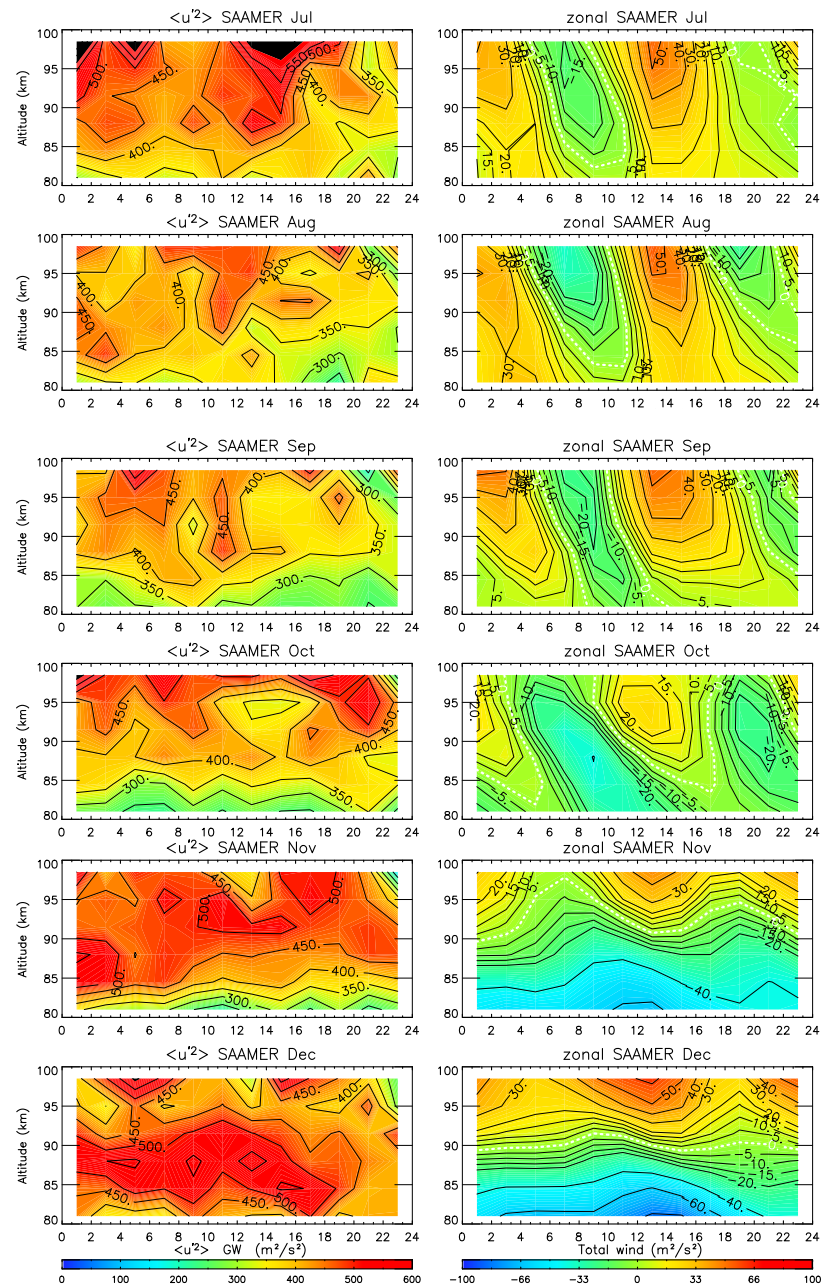

zonal SAAMER Sep
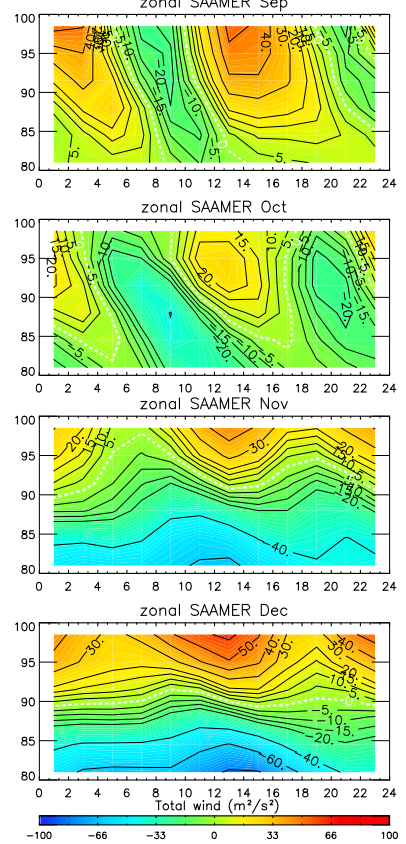

Fig. 11. The same as Fig. 9, but over Tierra Del Fuego during 2010.

A third mechanism associated with diurnal or semidiurnal modulations of potential GW sources, such as deep convection or mountain wave generation, could enable possible explanations for modulations that do not exhibit downward phase progression, especially in cases where filtering may be a weaker influence due to weak tidal winds or shears. But it appears unlikely that these GWs, with either isotropic or anisotropic phase speed distributions, would not also exhibit downward progression of variance maxima for larger tidal winds and wind shears.

Clemesha and Batista (2008) showed a good correlation between wind shear and the wind fluctuation related to GW activity. They also suggested that the wind shear in the MLT region due to tides could be a source for GWs. It is interesting to note that as long ago as 1968 Lindzen (1968) suggested that breaking of tides could lead to the generation instabilities which might produce gravity waves. As is well known, the diurnal tide with short vertical wavelength is dominant and has a semiannual oscillation with maximum amplitude at the equinoxes for the three Brazilian sites (see Batista et al., 2004; Andrioli et al., 2009; and Lima et al., 2007). It is interesting to note that all the variance modulations that show phase progression and good correlations with wind shear occur during equinoxes when the diurnal tide has a large amplitude: see, e.g., Fig. 5 (February, March and September), Fig. 6 (February to April, August to October), Fig. 7 (February to April and September), Fig. 8 (February to April and September), Fig. 9 (February to April and October), and Fig. 10 (February and March). Moreover, GWtidal interactions are strong when tidal amplitudes are large. These act both to remove GWs from the spectrum via filtering, as explained previously, and to excite additional GWs as part of the GW dissipation dynamics, though these dynamics have yet to be fully quantified and understood. As noted above, however, there are reasons to expect that GW-tidal interactions are a source of additional GWs, as suggested by Clemesha and Batista (2008). 

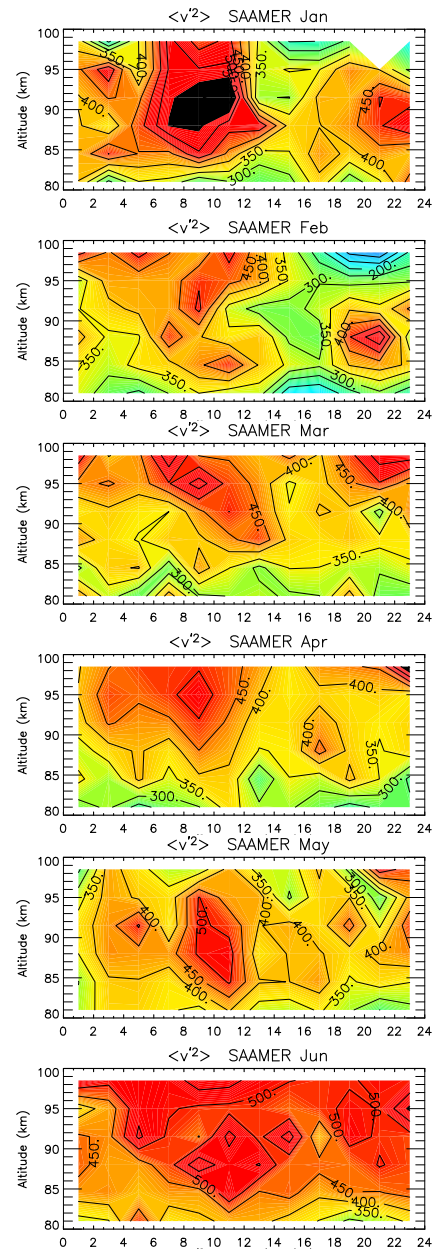

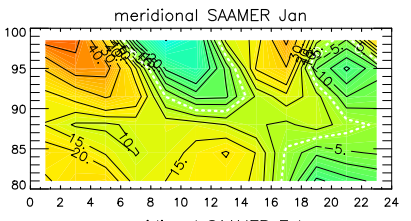

meridional SAAMER Feb
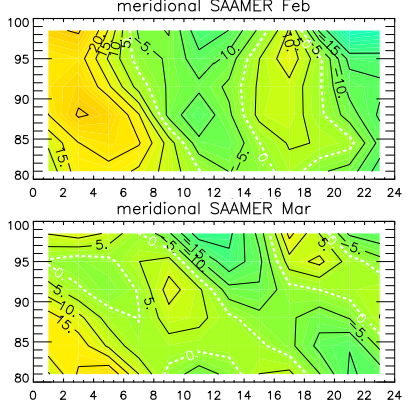

meridional SAAMER Apr
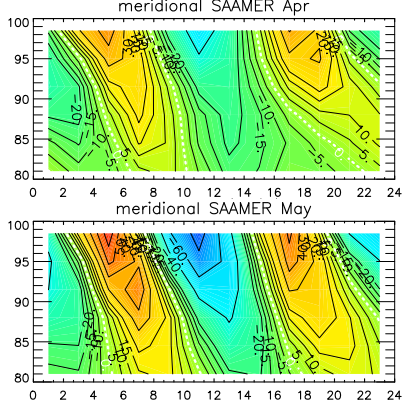

meridional SAAMER Jun

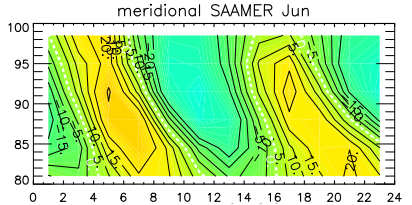

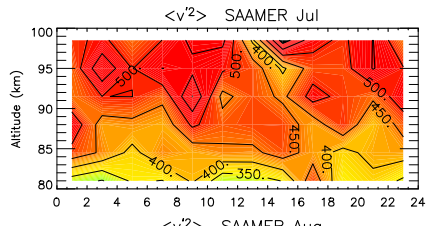
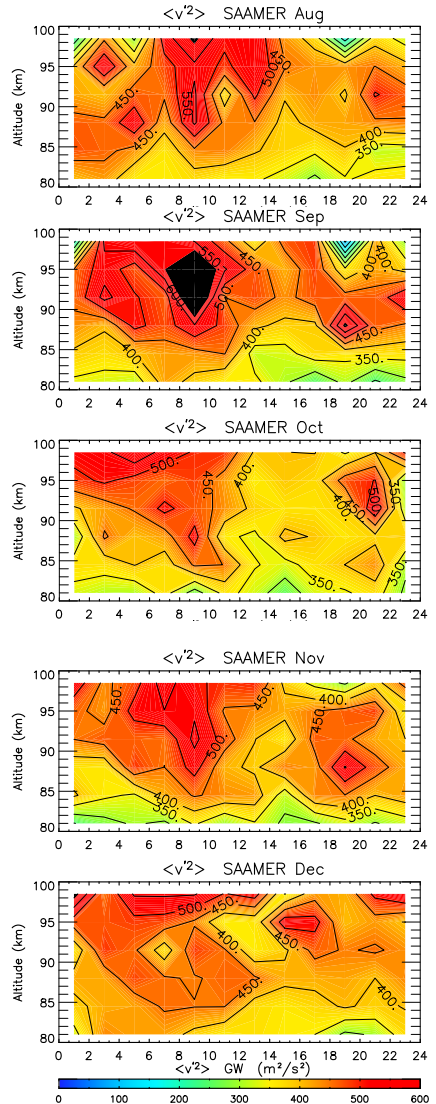

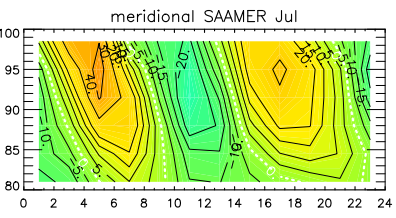

meridional SAAMER AUG
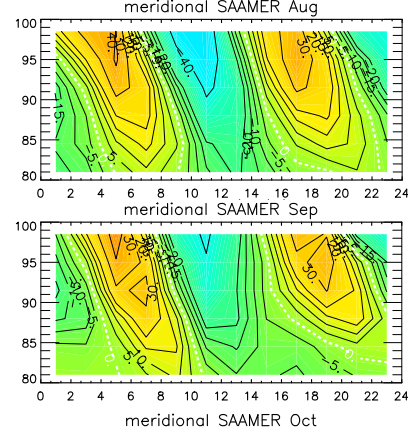

meridional SAAMER Oct

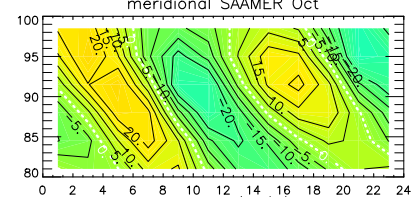

meridional SAAMER Nov

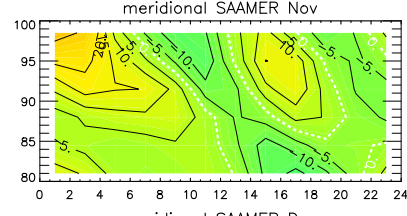

meridional SAMMER De

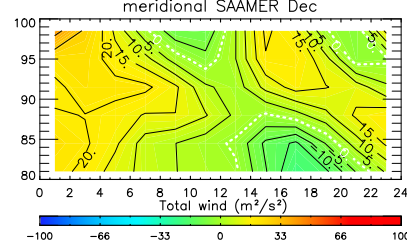

Fig. 12. The same as Fig. 11, but for the meridional component.

\section{Summary and conclusions}

We have presented a modified composite day analysis of allsky meteor radar data extending from $7^{\circ} \mathrm{S}$ to $53.6^{\circ} \mathrm{S}$. We observed diurnal and semidiurnal modulations of $\mathrm{GW}$ variances over all the sites. Semidiurnal modulations with downward phase progression were observed at lower latitudes, Cariri, $\mathrm{CP}$ and SM, and they occurred mainly near equinox. On the other hand, diurnal modulations occurred mainly near solstice and, except for the zonal component at Cariri, did not exhibit downward phase progression. At SAAMER at $53.6^{\circ} \mathrm{S}$, these modulations were only observed in the meridional component, with diurnal modulations from March to May and semidiurnal modulations during January, February, October (above $88 \mathrm{~km}$ ), and November. After making corrections to the variance estimates, as suggested by Andrioli et al. (2013), a number of observed modulations showed good correlations with wind shears. The most interesting

result of this work is that all the cases where the variance modulations show phase progression, and good correlations with wind shears, occur in the months where the diurnal tide achieves large amplitudes, e.g., near equinoxes.

Acknowledgements. The author V. F. Andrioli would like to acknowledge the FAPESP-process number 2012/08769-9, for supporting this work. Support for D. Fritts was provided by NSF Grants OPP-0839084 and AGS-1112830.

Topical Editor C. Jacobi thanks two anonymous referees for their help in evaluating this paper. 


\section{References}

Andrioli, V. F., Clemesha, B. R., Batista, P. P., and Schuch, N. J.: Atmospheric tides and mean winds in the meteor region over Santa Maria $\left(29.7^{\circ} \mathrm{S} ; 53.8^{\circ} \mathrm{W}\right)$, J. Atmos. Sol.-Terr. Phy., 71, 18641876, doi:10.1016/j.jastp.2009.07.005, 2009.

Andrioli, V. F., Fritts, D. C., Batista, P. P., and Clemesha, B. R.: Improved analysis of all-sky meteor radar measurements of gravity wave variances and momentum fluxes, Ann. Geophys., 31, 889908, doi:10.5194/angeo-31-889-2013, 2013.

Antonita, T. M., Ramkumar, G., Kumar, K. K., and Deepa, V.: Meteor wind radar observations of gravity wave momentum fluxes and their forcing toward the Mesospheric Semiannual Oscillation, J. Geophys. Res., 113, doi:10.1029/2007JD009089, 2008.

Batista, P. P., Clemesha, B. R., Tokumoto, A. S., and Lima, L. M.: Structure of the mean winds and tides in the meteor region over Cachoeira Paulista, Brazil $\left(22.7^{\circ} \mathrm{S} ; 45^{\circ} \mathrm{W}\right)$ and its comparison with models, J. Atmos. Sol.-Terr. Phys., 66, 623-636, doi:10.1016/j.jastp.2004.01.007, 2004.

Beldon, C. L. and Mitchell, N. J.: Gravity wave-tidal interactions in the mesosphere and lower thermosphere over Rothera, Antarctica $\left(68^{\circ} \mathrm{S}, 68^{\circ} \mathrm{W}\right)$, J. Geophys. Res., 115, D18101, doi:10.1029/2009JD013617, 2010.

Buriti, R. A., Hocking, W. K., Batista, P. P., Medeiros, A. F., and Clemesha, B. R.: Observations of equatorial mesospheric winds over Cariri $\left(7.4^{\circ} \mathrm{S}\right)$ by a meteor radar and comparison with existing models, Ann. Geophys., 26, 485-497, doi:10.5194/angeo26-485-2008, 2008.

Clemesha, B. R. and Batista, P. P.: Gravity waves and windshear in the MLT at $23^{\circ} \mathrm{S}$, Adv. Space Res., 41, 1471-1476, doi:10.1016/j.jastp.2008.01.013, 2008.

Clemesha, B. R., Batista, P. P., Buriti da Costa, R. A., and Schuch, N.: Seasonal variations in gravity wave activity at three locations in Brazil, Ann. Geophys., 27, 1059-1065, doi:10.5194/angeo27-1059-2009, 2009.

Forbes, J. M., Gu, J., and Miyahara, S.: On the interactions between gravity waves and the diurnal tide, Planet. Space Sci., 39, 12461257, 1991.

Fritts, D. and Alexander, M. J.: Gravity wave dynamics and effects in the middle atmosphere, Rev. Geophys, 41, 3.1-3.64, doi:10.1029/2001RG000106, 2003.

Fritts, D. C. and Vincent, R. A.: Mesospheric momentum flux studies at Adelaide, Australia: Observations and a gravity wave/tidal interaction model, J. Atmos. Sci., 44, 605-619, 1987.

Fritts, D. C., Janches, D., and Hocking, W. K.: Southern Argentina Agile Meteor Radar: Initial assessment of gravity wave momentum fluxes, J. Geophys. Res., 115, D19123, doi:10.1029/2010JD013891, 2010.

Fritts, D. C., Janches, D., Hocking, W. K., Bageston, J. V., and Leme, N. M. P.: Drake Antarctic Agile Meteor Radar (DrAAMER) First Results: Configuration and Comparison of Mean and Tidal Wind and Gravity Wave Momentum Flux Measurements with SAAMER, J. Geophs. Res., 117, D02105, doi:10.1029/2011JD016651, 2012a.

Fritts, D. C., Janches, D., Hocking, W. K., Mitchell, N. J., and Taylor, M. J.: Assessment of gravity wave momentum flux measurement capabilities by meteor radars having different transmitter power and antenna configurations, J. Geophys. Res., 117, D10108, doi:10.1029/2011JD017174, 2012b.
Hocking, W. K.: A new approach to momentum flux determinations using SKiYMET meteor radars, Ann. Geophys., 23, 2433-2439, doi:10.5194/angeo-23-2433-2005, 2005.

Isler, J. R. and Fritts, D. C.: Gravity-wave variability and interaction with lower-frequency motions in the mesosphere and lower thermosphere over Hawaii, J. Atmos. Sci., 53, 37-48, 1996.

Lima, L. M., Batista, P. P., Clemesha, B. R., and Takahashi, H.: Quasi-two-day wave observed by meteor radar at 22.7 S. J. Atmos. Sol.-Terr. Phys., 66, 529-537, doi:10.1016/j.jastp.2004.01.007, 2004.

Lima, L. M., Batista, P. P., Clemesha, B. R., and Takahashi, H.: The 6.5-day Oscillations observed in Meteor Winds over Cachoeira Paulista (22.7 S), Adv. Space Res., 36, 2212-2217, 2005.

Lima, L. M., Batista, P. P., Clemesha, B. R., and Takahashi, H.: 16-day wave observed in the meteor winds at low latitudes in the southern hemisphere, Adv. Space Res., 38, 2615-2620, doi:10.1016/j.asr.2006.03.033, 2006.

Lima, L. M., Paulino, A. R. S., Medeiros, A. F., Buriti, R. A., Batista, P. P., Clemesha, B. R., and Takahashi, H.: First observation of the diurnal and semidiurnal oscillation in the mesospheric winds over São João do Cariri-PB, Brazil, Rev. Bras. Geofísica, 25, 35-41, doi:10.1590/S0102-261X2007000600005, 2007.

Lindzen, R. S.: The application of classical atmospheric tidal theory, Proc. Roy. Soc. A, 303, 299-216, 1968.

Lu, W. and Fritts, D. C.: Spectral estimates of gravity wave energy and momentum fluxes, III: Gravity wave-tidal interactions, J. Atmos. Sci., 50, 3714-3727, 1993.

Manson, A. H., Meek, C. E., Qian, J., and Gardner, C. S.: Spectra of gravity wave density and wind perturbations observed during Arctic Noctilucent Cloud (ANLC-93) campaign over the Canadian Prairies: Synergistic airborne Na lidar and MF radar observations, J. Geophys. Res., 103, 6455-6466, 1998.

Mayr, H. G., Mengel, J. G., Chan, K. L., and Porter, H. S.: Seasonal variations of the diurnal tide induced by gravity wave filtering, Geophys. Res. Lett., 25, 943-946, 1998.

Meyer, C. K: Gravity wave interactions with the diurnal propagating tide, J. Geophys. Res., 104, 4223-4239, 1999.

Ortland, D. A. and Alexander, M. J.: Gravity wave influence on the global structure of the diurnal tide in the mesosphere and lower thermosphere, J. Geophys. Res., 111, A10S10, doi:10.1029/2005JA011467, 2006.

Placke, M., Stober, G., and Jacobi, Ch.: Gravity wave momentum fluxes in the MLT - Part I: Seasonal variation at Collm $\left(51.3^{\circ} \mathrm{N}, 13.0^{\circ} \mathrm{E}\right)$, J. Atmos. Sol.-Terr. Phys., 73, 904-910, doi:10.1016/j.jastp.2010.07.012, 2011a.

Placke, M., Hoffmann, P., Becker, E., Jacobi, C., Singer, W., and Rapp, M.: Gravity wave momentum fluxes in the MLT - Part II: Meteor radar investigations at high and midlatitudes in comparison with modelling studies, J. Atmos. Sol.-Terr. Phys., 73, 911-920, doi:10.1016/j.jastp.2010.05.007, 2011b.

Thayaparan, T., Hocking, W. K., and MacDougall, J.: Observational evidence of tidal/gravity wave interactions using the UWO 2 MHz radar, Geophys. Res. Lett., 22, 373-376, 1995.

Vadas, S. L. and Fritts, D. C.: Gravity wave radiation and mean responses to local body forces in the atmosphere, J. Atmos. Sci., 58, 2249-2279, 2001.

Vadas, S. L. and Fritts, D. C.: The importance of spatial variability in the generation of secondary gravity waves 
from local body forces, Geophys. Res. Lett., 29, 1984, doi:10.1029/2002GL015574, 2002.

Vincent, R. A. and Reid, I. M.: HF Doppler measurements of mesospheric gravity wave momentum fluxes, J. Atmos. Sci., 40, 13211333, 1983.

Walterscheid, R. L.: Inertio-gravity wave induced accelerations of mean flow having an imposed periodic component: Implications for tidal observations in the meteor region, J. Geophs. Res., 86, 9698-9706, 1981.
Wang, D. Y. and Fritts, D. C.: Evidence of gravity wave-tidal interaction observed near the summer mesopause at Poker Flat, Alaska, J. Atmos. Sci., 48, 572-583, 1991. 